\title{
EFFECTS OF PARTNERING ELEMENTS: AN EXPLORATORY CASE STUDY
}

\author{
Marta Røer Falch ${ }^{1}$, Atle Engebo ${ }^{2}$, and Ola Lædre ${ }^{3}$
}

\begin{abstract}
Partnering elements have become more common in Norwegian construction projects over the last decades. Partnering, as a project delivery method, shares similarities with the lean perspective as they both use available elements to achieve a collaborative project. The LC principles are often illustrated in terms of three fundamental elements (commercial, organizational, and operating system). This aligns with how this paper has categorised partnering, into contractual-, organisational-, and cultural elements. Consequently, this paper contributes to knowledge about the effects of partnering elements by answering the two research questions: 1) Which elements are used in partnering projects, and 2) What are the effects of these elements.

An exploratory case study of a partnering project was carried out to examine the partnering elements and their effects. A combination of literature review, document study and semi-structured interviews were used data collection.

The findings reveal that the contractual-, organisational-, and cultural elements are aligned with the LC triangle. There is a potential when implementing lean elements in partnering. However, there is a risk for partnering projects falling into a traditional approach in the actual delivery. The paper concludes that more attention should be paid to the effects of organisational and cultural elements in partnering projects.
\end{abstract}

\section{KEYWORDS}

Lean project delivery, project delivery methods, integrated teams, collaboration, partnering

\section{INTRODUCTION}

By tradition, the construction industry has viewed project delivery as a transactional matter, where contracts are used to allocate capital to the bidder that could deliver on the lowest costs when providing their services. However, as projects are becoming more complex and the industry more specialized, more actors change their way of viewing project delivery. For a longer time, there has been written about an efficiency potential in the construction industry in Norway. The challenges are complex and incorporated in the industry; it is, therefore, challenging to solve (Ingvaldsen and Edvardsen 2007).

1 MS Student, Department of Civil and Environmental Engineering, Norwegian University of Science and Technology (NTNU), Trondheim, Norway, mcfalch@stud.ntnu.no, orcid.org/0000-0001-9919$\underline{5933}$

$2 \mathrm{PhD}$ Candidate, Department of Civil and Environmental Engineering, NTNU, Trondheim, Norway, atle.engebo@ntnu.no, orcid.org/0000-0002-5293-0176

3 Professor, dr. ing., Department of Civil and Environmental Engineering, NTNU, Trondheim, Norway, ola.ladre@ntnu.no, orcid.org/0000-0003-4604-8299 
Under the term 'Partnering', integrated forms of project delivery have increasingly been implemented in construction projects in Norway in the last decades (Hosseini et al. 2018). Partnering is an integrated form of project delivery, and mean the degree to which different project elements, such as planning, design, construction, and operation, are segmented or combined during the production cycle, are implemented (Miller et al. 2000). The approach is characterized by, i.e. early involvement, dialogue, trust, and openness in projects. The fundamental belief is that seeking integration through various elements, the project delivery method would result in savings, increased value, and project optimization (EBA 2013, Hosseini et al. 2016).

In Norway today, a standardised partnering contract does not exist. This leads to no unified practice. Therefore, we break partnering projects into elements that all are intended to increase integration in the project delivery. This study relies on previous research efforts regarding mapping and categorizing these elements (Aslesen et al. 2018, Eriksson 2010, Haugseth et al. 2014, Hosseini et al. 2016, Wøien et al. 2016). The research has shown that there currently exists no best practice as to which elements to be applied. Hence, the right elements to implement are depending on project characteristics and its organisation (Hosseini et al. 2016).

According to literature on lean, lean project delivery methods operate with collaborative elements such as integrated teams, early involvement of actors, Target Cost Contracts, and Target Value Design (Alarcón et al. 2013). This aligns well with how this paper has categorized elements, into contractual elements (i.e., target cost), organisational elements (i.e., performance measurements), and cultural elements (i.e., collaboration culture) (Engebø et al. 2020).

This paper investigates contractual-, organisational-, and cultural elements in one specific partnering project through the following research questions:

- RQ1: Which elements are used in the partnering project?

- RQ2: What are the effects of these elements?

This paper reports mainly on a case study of a large Norwegian contractor (Backe StorOslo, hereafter BSO), included perspectives from the project owner and two subcontractors. The interviewees have expertise in integrated forms of project delivery. By implementing integration-enhancing elements in suitable projects, BSO has seen a cost reduction in terms of fewer errors and better quality. Therefore, the purpose of this paper is to document experiences and contribute to the knowledge transfer of the effects of partnering elements.

To limit the scope of the research, this paper is mainly focusing on project execution. However, it was natural to incorporate some data concerning the design phase since these two phases are mutually dependent (especially regarding explanations of causes- and effects). A lot of literature exists on partnering elements, and this paper describes in depth results from organisational and cultural elements separately. The contractual elements are however investigated and further put in the context of Adair's leadership model, since they all have an important impact on how teams perform. One partnering project is chosen to study, as the researchers were given entry and access to the whole project.

\section{METHODOLOGY}

The research design is based on an exploratory case study of a partnering project with BSO and a public project owner. The choice of studying one partnering project was considered methodologically suitable as the researchers were given entry and access to 
the whole project. Since 9 of 12 interviewees had experience with several housebuilding partnering projects, this made it possible to collect comparative empirical data.

To study contractual-, organisational-, and cultural elements, a review of relevant literature was first conducted. The literature review was carried out by following the prescriptions of Arksey and O'Malley (2005). A structured literature search was conducted in five databases (Oria, Web of Science, Scopus, Science Direct, and ASCE). The literature was assessed by considering the publications in the given order: Title, keywords, abstract, conclusion and the publication itself. If the publication was thematically relevant, its credibility and reliability were assessed.

In means of data collection, the study draws its empirical insight from semi-structured interviews and documents retrieved from the studied organisation. The data collection process followed the case study approach outlined by Yin (2018) by first gaining access to an organisation, and then developing a procedure for data collection activities. For the interviews, an interview-guide (Protocol Questions) that followed the research questions was developed. After that, the project was screened, and 12 relevant candidates were recruited. The interviewees were key persons in the project and represented a crosssection of actors and roles involved in the project (both client and contractor representatives). The interviews were personal semi-structured interviews, an explorative and dialogue-based interview form (Saunders et al. 2016). Each interview lasted for approximately one hour, it was recorded and later transcribed.

A document study was also performed as a method for triangulation. The documents included the Partnering contracts used for the execution- and design phase, meeting minutes and technical project specifications. The documents investigated aided the researcher in verifying the contractual-, organisational-, and cultural elements used in the project. In some instances, they also provided specific details that supplemented and confirmed data from the interviews.

Lastly, the data were analysed by searching for themes and patterns in the data and then seen in the context of the research questions. The data was, therefore, coded using a set of preselected investigated elements, see Table 1 . Hence, the themes were the elements used in partnering projects (RQ1), and the codes were the effects attached to each theme (RQ2).

Table 1: Preselected investigated elements

\begin{tabular}{|c|c|c|}
\hline Contractual elements & Organisational elements & Cultural elements \\
\hline Team composition & IT-tools & $\begin{array}{c}\text { Project- and collaboration } \\
\text { culture }\end{array}$ \\
\hline $\begin{array}{l}\text { Target price (Shared } \\
\text { risk/reward) }\end{array}$ & Co-location & Common goals/delivery \\
\hline Conflict resolution mechanism & Start-up seminar & Identity/relation-building \\
\hline $\begin{array}{c}\text { Obligation, risk, uncertainty } \\
\text { distribution }\end{array}$ & Production control & $\begin{array}{c}\text { Communication/information } \\
\text { sharing }\end{array}$ \\
\hline Right to replace people & Performance measurements & Competence sharing \\
\hline Open book & & Conflicts \\
\hline Project specifications & & $\begin{array}{l}\text { Commitments and } \\
\text { dependencies }\end{array}$ \\
\hline Shared decision making & & $\begin{array}{l}\text { Support from management } \\
\text { (organisational and project) }\end{array}$ \\
\hline
\end{tabular}


The authors used a list of partnering elements from earlier studies (Aslesen et al. 2018, Eriksson 2010, Haugseth et al. 2014, Hosseini et al. 2016, Wøien et al. 2016). The substantial list of elements from the literature was cross-checked with the case project. Subsequently, the authors modified the list to fit the project by removing some elements not present and eventually adding new ones if they emerged from the project itself. The selected elements were tested in the interviews. The list worked well and was therefore used throughout the study.

\section{LITERATURE REVIEW}

\section{COLLABORATIVE PROJECT DELIVERY METHODS}

A core principle of lean project delivery lies within aligning the contractual elements (contract), the project organization, and production (design and production), also referred to as the lean construction (LC) triangle (Ballard 2012, Howell 2011, Thomsen et al. 2009). The LC triangle, see Figure 1, illustrates the three fundamental elements in all project delivery methods (commercial, organizational and operating system). Lean project delivery seeks to align all project parties with available contractual elements to achieve a collaborative project organization. This will lead to a project culture for delivering value in production.

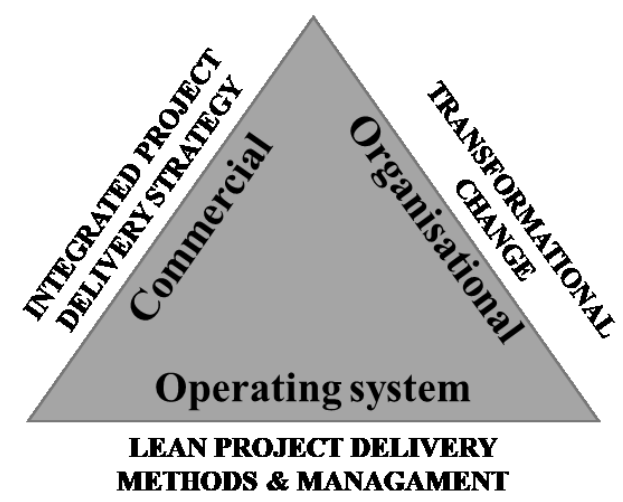

Figure 1: Modified lean construction triangle, originally from Thomsen et al. (2009), updated by the Lean Construction Institute (2016)

On the topic of public procurement, most public agencies do not have the legal authority to implement Lean IPD using a relational three-or-more-party agreement (Darrington 2011). Therefore, a design-build delivery method has become a popular alternative. This is, somewhat, supported by Hosseini et al. (2016) stating that no sets of elements must be included to identify the project as partnering. Choosing the right elements, depends on project type- and phase. Contractual elements for partnering are extensively studied and mapped (Eriksson et al. 2008, Willcocks and Kern 1998, Wøien et al. 2016). Henceforth, when the contract is signed, the contractual elements are usually fixed. This sets the framework for collaboration and how the project culture develops (Larssen et al. 2019). Organisational and cultural elements are, on the other hand, often implemented during the project progress. Therefore, when these elements should be implemented, must be considered separately.

Within a project delivery method, a vast array of tools and techniques (organisational elements) are available for the management. For Lean Project Delivery, this may be Pull Scheduling (Tommelein 1998), Set Based Design (Parrish et al. 2008), Last Planner(R) 
system (Ballard 2000), Performance Measurements (Belsvik 2019), and co-location (Fischer 2017).

A central aspect of partnering is the combination of classical transactional contracts between client and suppliers, and that it simultaneously seeks to bind the actors through relational contracts. This is done by establishing a project culture that fosters relationships beyond the mere transaction of services (Matthews and Howell 2005).

The project culture is often an overlooked aspect of project delivery, but this should not be the case as it affects the behaviour of the actors and, consequently, the performance. Zuo and Zillante (2005) state that a positive (positive, strong, co-operative, and collaborative) project culture should be developed and maintained. Furthermore, a lean project culture should emphasise long-term decisions, opportunities for improvement, and open dialog with all levels of the organization (Paro and Gerolamo 2017). Some indicators for a good project culture are top management support, trust, shared goals and motivation, attaining the right people, and openness and transparency (Engebø et al. 2020).

Optimal teamwork is depending on a wide array of factors. To make the topic approachable researchers have developed models that illustrate how to optimize teams in a practical matter. Adair (1988) presents a model for an integrated team, where the three basic needs, team-, task-, and individual needs, should be met to optimize the teamwork. The model indicates that if cooperation does not work, it is due to a lack of one or more needs. Integrated teams mean that individuals from various organisations work together to achieve common attainable project goals through the sharing of information. This means that different company processes and organisational cultures must be aligned in a collaborative manner (Baiden et al. 2006). From a lean perspective, integrated teams are viewed as a means for delivering value for all actors in the project. As Forgues et al. (2008) write, integrated teams will through collaboration, seek to provide superior value by assembling, integrating, and harnessing all the collective skills and capabilities of clients and their supply chains.

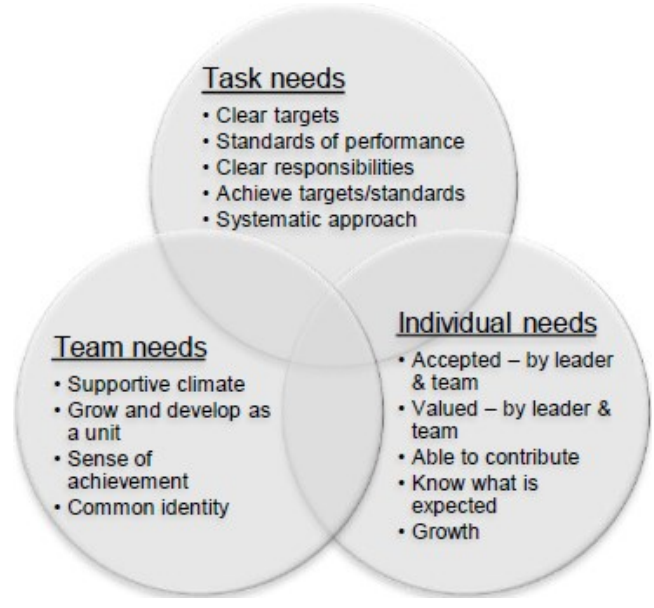

Figure 2: Integrated team model for leadership needs (Adair 1988)

The overlapping areas in Figure 2 illustrate the importance of remembering and combineing the needs throughout the project. Various elements will affect different needs uniquely. Some have specific effects i.e. only affecting one need, while others support two or three needs simultaneously. For instance, open-book supports the task need, whereas a start-up seminar promotes team-, task-, and individual needs (Oakland and Marosszeky 2017, Simonsen et al. 2019). 


\section{FINDINGS AND DISCUSSION}

This paper presents an effort to map key contractual-, organisational-, and cultural elements that are used in partnering. This structure follows the LC-triangle, as Thomsen et al. (2009) argue, project delivery methods may be described within the domains of project organization, the projects "operating system" and the commercial terms (contract). The research complements by documenting how the key contractual-, organisational-, and cultural elements are practiced and their potential effects. These findings were collected from the experience of one particular partnering project, but the elements studied are used widely in the industry.

\section{CONTRACTUAL ELEMENTS}

Contractual elements being the most tangible category and, according to the literature, the most extensively studied and mapped category, see for example Eriksson et al. (2008), Willcocks and Kern (1998), and Wøien et al. (2016). Consequently, as stated in the limitations of the paper, contractual elements will not be elaborated upon. Instead, for the emphasis is put on organisational- and cultural elements. The main contractual elements used in this project was a weight on team composition in the selection process, the use of Target price contract (Shared risk/reward) with clear obligation-, risk,- and uncertainty distribution, having a formal conflict resolution mechanism, having a contractual right to replace people, economic transparency through using open book, and shared decision making between participants. However, the contractual elements of the project (listed in Table 1) will none-the-less have an impact on the project and team performance and are therefore put in the context of Adair's leadership model (1988), see Table 2.

\section{ORGANISATIONAL ELEMENTS}

The interviewees have worked with different IT-tools. BSO aims to use the same tools in all projects independently of the project delivery method. Therefore, partnering projects use the same IT-tools as in traditional projects. The interviewees indicated that the tools are not utilised differently in partnering, and not implemented specifically because of partnering. On the other hand, the interviewees believe that IT-tools provide a positive effect on information flow and collaboration. In total, they mean that the tools result in fewer errors and better quality.

A critical organisational element in partnering is the use of co-location as it enables communication and knowledge sharing. Co-location means that the key project participants physically meet and work together at least once a week. All interviewees were familiar with the use of co-location. Two interviewees told that co-location was an enabling factor for creating an effective collaborative climate. It can be challenging with a well-working collaboration climate without co-location as team bonding gets harder. But Co-location alone is not a prerequisite for success, it is the richness in communication and information sharing that contributes to collaboration. What is needed, are project participants available for the project.

The interviewees had experience with start-up seminars before the design- and execution phase. Whilst the guiding principle of start-up seminars are to improve social relations and clarify goals, it can be perceived as "soaring." One interviewee describes a tendency by the management to use big and empty words, and a forgotten outcome after a brief time. The interviewee sought a more "hands-on" approach related to, e.g., success criteria and common goals. There are, nevertheless, reasons to consider start-up seminars as important for project progress; it gives crucial commitments and relationships. 
How Production control is practiced depends on the project owner's expectations. The contractor aligns themselves with the project owner, which means the production control is not depending on the project delivery method. Some project owners are just interested in a few milestones, while others want a weekly updated plan of nearby finished and upcoming works. None of the interviewees tell about a unique way of control production in partnering. For specific suggestions about production control, it may need more investigations. We posit this as an area for improvement, as a vast array of elements are available such as Pull Scheduling (Tommelein 1998), Set Based Design (Parrish et al. 2008), and Last Planner(R) (Ballard 2000).

The interviewees did not have much experience with performance measurements beyond documenting, e.g. production rate and number of injuries, and so on. However, they all consider it as interesting and an area for improvement. One of the interviewees stated that performance measurements are challenging to implement in the contemporary organisational structure. One can argue that project teams being inter-organisational coupled with unclear deliverables in the design process, is a reason of why performance measurements often are absent. Regardless, performance measurements should be a backbone in any process, as improvements cannot occur if nothing is measured. Performance measures seem to be the organisational elements where Partnering has the most potential for improvement, for example by being aligned with lean principles. In a lean construction perspective, implementation of performance measurements is a real driver for continuous improvement of project processes (Alarcón and Serpell 1996).

\section{Cultural elements}

Project- and collaboration culture is an often-overlooked aspect of project delivery to achieve long-term benefits. As stated by Stehn and Höök (2008), there is a need for a cultural change towards a lean culture and, consequently, focus on individuals is an essential part of achieving a lean culture. Therefore, viewing and being deliberate about cultural elements is essential. The interviewees highlighted establishing a collaborative culture as the most important cultural element. Essentially, when a collaborative culture is established, it needs to remain during the whole project. Nevertheless, a collaborative culture is not unique in partnering projects. One interviewee tells about a traditional project with better collaboration than a comparable partnering project. However, in a partnering project the project delivery method should be aligned in such way that it facilitates collaboration. In project delivery with successful collaboration, the contributors have positive thoughts of each other, are involved early, and a shared understanding of the project delivery is well established.

The interviewees considered an agreement and understanding related to common goals/delivery. Shared goals must be viewed as a core value for all partnering project as it is one main element for collaboration. If all actors agree on this, it provides a set of coherent conditions to comply with. However, one interviewee missed specific project goals. The project goals were general, such as zero injuries and a project achieving agreed quality. The person missed specific project goals. Was, for instance, conditions outside the particular delivery relevant? For a wider understanding, the actors can together specify the most crucial project goals/deliveries.

The interviewees stated that relation/identity-building is a continuous process that must be worked on throughout the whole project. This is not a standardised element as it varies, both internally and externally, during the projects. Yet, what is seen is that the relation/identity-building tend to be emphasised early on, but then decline as the project 
progresses. By building necessary relations with other participants, it provides a mutual commitment to each other and the project. This can be rectified through common activities, where relationships occur irrespective of the actor. Consequently, identitybuilding activities should be revised as the project progresses.

The interviewees found communication and information sharing as a challenging element. The interviewees had mixed experiences with the element in partnering. For some, communication and information sharing were rather straightforward. For others, it was demanding. Since it is a relational aspect, expecting all participants to talk and deliver necessary information at the right time is difficult. Projects with effective communication/information sharing, result in openness and trust and are, therefore, tightly coupled to the collaborative culture and identity-building. Challenges should be identified early, and solved by, e.g., frequent meetings and facilitated using organisational elements, such as co-location.

Competence composition is correlated to the contractual element, team composition, as the project team is often contracted. One interviewee meant, therefore, that competence composition also is a fixed element. Necessary competency provides a better prerequisite, and the appropriate competence at the right time is essential to succeed with partnering. Yet, as the competence is "fixed", how the team utilised the competence of the individuals is a different story.

The interviewees tell about slightly no experience in handling conflicts. Disagreements have occurred, but this is not considered a conflict. A conflict resolution mechanism is contractual, and the interviewees meant it had a positive effect on the project, in terms of preventing arising conflicts. Clarifications on how to handle conflicts are essential in advance of well-functioning collaboration during a conflict situation.

According to an interviewee, managing commitments and dependencies in projects are demanding. In a partnering project, getting all actors to commit to both the process and project may be a key success criterion. For managers, this is important as some individuals are less autonomous and need to be closely followed-up. The same principle applies to create commitments. For example, one interviewee said his sense of commitment and dependence progressed after interacting with the users. The person felt a stronger commitment to the product when users were involved because it created a sense of real project importance. Subsequently, an insight into successful partnering may be to create a stronger commitment to users. Commitments and dependencies should be coupled with the element of establishing common goals and co-location as those elements strengthen commitments. Especially in removing the interface between users and designers (getting them to interact).

The interviewees felt the sense of support from management (organisational and project) differently depending on each project. Both the project organisation as a unit and the individuals in the organisation must receive the necessary support. The perception of support from management gives extra motivation. This will add value to the organisation.

Repeating Stehn and Höök (2008), Engebø et al. (2019), and Simonsen et al. (2019), there is a need for a lasting cultural change to achieve collaboration through the construction process. We highlight that most elements affect the task- and team needs, but the individuals in the process are still somewhat overlooked.

\section{CONCLUSIONS}

The paper broadens the understanding of the effect of key contractual-, organisational-, and cultural elements commonly used in partnering, which can be recognised from the 
LC-triangle. The Partnering elements identified in this case is analysed based on the data from the interviews and, conceptualised as to how they affect task, team, and/or individual needs. Consequently, Table 2 summarizes how each of the investigated partnering elements affects the three fundamental needs, task, team, and individual needs, described in Adair's leadership model (1988).

Table 2: Partnering elements affecting task, team, and/or individual needs

\begin{tabular}{|c|c|c|c|c|}
\hline & & Task & Team & Individual \\
\hline \multirow{8}{*}{$\begin{array}{l}\text { Contractual } \\
\text { elements }\end{array}$} & Team composition & $x$ & $x$ & $x$ \\
\hline & Target price (Shared risk/reward & $x$ & & \\
\hline & Conflict resolution mechanism & $\mathrm{X}$ & $x$ & \\
\hline & Obligation, risk, uncertainty distribution & $x$ & $x$ & \\
\hline & Right to replace people & & $x$ & \\
\hline & Open book & $x$ & & \\
\hline & Project specifications & $X$ & & \\
\hline & Shared decision making & $\mathrm{X}$ & $\mathrm{X}$ & $\mathrm{x}$ \\
\hline \multirow{5}{*}{$\begin{array}{l}\text { Organisational } \\
\text { elements }\end{array}$} & IT-tools & $x$ & & \\
\hline & Co-location & $x$ & $\mathrm{X}$ & \\
\hline & Start-up seminars & $x$ & $x$ & $x$ \\
\hline & Production control & $x$ & & \\
\hline & Performance measurements & $x$ & & \\
\hline \multirow{8}{*}{$\begin{array}{l}\text { Cultural } \\
\text { elements }\end{array}$} & Project- and collaboration culture & & $\mathrm{X}$ & $\mathrm{X}$ \\
\hline & Common goals/ delivery & $x$ & $\mathrm{X}$ & \\
\hline & Relation/ identity-building & & $x$ & $x$ \\
\hline & $\begin{array}{l}\text { Communication and information } \\
\text { sharing }\end{array}$ & $x$ & $x$ & \\
\hline & Competence composition & $\mathrm{X}$ & & \\
\hline & Handling conflicts & & $\mathrm{X}$ & \\
\hline & Commitments and dependencies & & $\mathrm{X}$ & $x$ \\
\hline & Support from management & & $X$ & $X$ \\
\hline
\end{tabular}

As illustrated in Table 2, the contractual elements mainly affect task needs. These elements are concrete, and often characterising the formal project delivery method. Nevertheless, a project with a traditional delivery method - without these contractual elements - can still achieve a collaborative culture. Similarly, a partnering project with these contractual elements that fails to achieve a collaborative culture will probably not perform better than a project with a traditional delivery method. To create an effective delivery team, organisational and cultural elements should be added in the project delivery method to promote team and individual needs.

Projects formally considered as partnering may be very traditionally organised in the execution phase. This may happen because of lack of attention towards collaborationenhancing organisational and cultural elements. As can be seen in Table 2, the 
organisational elements are primarily affecting task needs. Implementing lean methods in the execution phase can enforce the organisational elements and positively affect task and individual needs. For example, the Last Planner(R) system could be implemented for production control. There is a synergy potential when combining Lean elements in partnering.

Cultural elements affect team needs more than contractual and organisational elements do. Furthermore, the cultural elements affecting individual needs are also affecting team needs (i.e. support from management), while cultural elements affecting team needs are not always affecting individual needs (i.e. handling conflicts). No elements are affecting individual needs alone. Which cultural elements to implement should be coupled with project characteristics. Therefore, this must be considered separately. The importance of a good project- and collaboration culture is widely recognised, but it is also by definition hard to define and replicate in projects. The cultural elements described here was perceived to be essential in this case. By showing how these elements affected the project team we highlight that culture can, to a certain degree, be managed or shaped. Thus, this study underlines the importance of cultural elements because they affect individual- and team needs.

It was challenging to get the interviewees to elaborate on cultural elements, and there are at least two possible reasons for this. First, as the cultural elements came in the last part of the interview, the interviewees often answered that this had already been touched upon when the contractual elements were discussed. Second, cultural elements are relational and less tangible than organisational and contractual elements. However, after being challenged to reflect on the cultural elements, the interviewees stated that they are important for project success.

\section{FURTHER WORK}

The cultural elements in partnering projects are essential to investigate, and this study is a beginning on mapping these elements. Therefore, future research on cultural elements is needed.

\section{REFERENCES}

Adair, J. 1973. Action-centred leadership, The Industrial Society. New York: McGrawHill,

Alarcón, L. F., Mesa, H. and Howell, G. 2013. "Characterization of lean Project delivery". Proc. 21st Annual Conference of the International Group for Lean Construction (IGLC). Fortaleza, Brazil, 31-2 Aug 2013. pp 247-255.

Alarcón, L. F. and Serpell, A. 1996. "Performance measuring benchmarking, and modelling of construction projects." Proc. 4th Annual Conference of the International Group for Lean Construction, Birmingham, U.K.

Arksey, H. and O'Malley, L. 2005. Scoping studies: towards a methodological framework. International Journal of Social Research Methodology, 8(1), pp 19-32.

Aslesen, A. R., Nordheim, R., Varegg, B. and Lædre, O. 2018. "IPD in Norway." Proc. 26th Annual Conference of the International Group for Lean Construction (IGLC). Chennai, India, 18-20 Jul 2018. pp 326-336.

Baiden, B. K., Price, A. D. and Dainty, A. R. 2006. "The extent of team integration within construction projects." International journal of project management, 24, pp 13-23. 
Ballard, G. 2012. "Should Project budgets be based on worth or cost." Proc. 20th Annual Conference of the International Group for Lean Construction (IGLC). San Diego, USA. 2012. pp 761-770.

Ballard, G. 2000. The last planner system of production control. Doctoral thesis, Civil Engineering, University of Birmingham, School of Civil Engineering. Birmingham, U.K.

Belsvik, M. R., Lædre, O., Hjelseth, E. 2019. Metrics in VDC Projects. Proc. 27th Annual Conference of the International Group for Lean Construction (IGLC). Dublin, Ireland, 3-5 Jul 2019. pp 1129-1140.

Darrington, J. 2011. "Using a design-build contract for Lean Integrated Project Delivery." Lean Construction Journal. 8(1), pp 85-91.

EBA 2013. Veileder om samspillsentreprise. www.anskaffelser.no.

Engebø, A., Lædre, O., Young, B., Larssen, P. F., Lohne, J. and Klakegg, O. J. 2020. Collaborative project delivery methods": a scoping review. Journal of Civil Engineering and Management, 26(3), 278-303.

Engebø, A., Skatvedt, Å. and Torp, O. 2019. "Soft Elements in Collaborative Project Delivery Methods." Proc. 27th Annual Conference of the International Group for Lean Construction (IGLC). Dublin, Ireland, 3-5 Jul 2019. pp 773-784.

Eriksson, P. E. 2010. "Partnering: What is it, when should it be used, and how should it be implemented?." Construction Management and Economics, 28(9), pp 905-917.

Eriksson, P. E., Nilsson, T. B. and Atkin, B. 2008. Client perceptions of barriers to partnering." Engineering, Construction and Architectural Management. 15(6), pp 527-539.

Fischer, M. A., Howard W; Reed, Dean; Khanzode, Atul 2017. Integrating project delivery, John Wiley and Sons. New Jersey, USA.

Forgues, D., Koskela, L. and Lejeune, A. 2008. «Breaking socio-cognitive barriers to value generation in integrated teams." Proc. 16th Annual Conference of the International Group for Lean Construction (IGLC). Manchester, UK, 16-18 Jul 2008. pp 435-46.

Haugseth, N., Lohne, J., Jensen, G. and Lædre, O. 2014. "Partnering in Statsbygg." 22nd Annual Conference of the International Group for Lean Construction (IGLC). Oslo, Norway, 25-27 Jun 2014. pp 1343-1356.

Hosseini, A., Wondimu, P., Klakegg, O. J., Andersen, B. and Laedre, O. 2018. "Project partnering in the construction industry": Theory vs. practice. Engineering Project Organization Journal, 8, pp 2-24.

Hosseini, A., Wondimu, P. A., Bellini, A., Haugseth, N., Andersen, B. and Lædre, O. 2016. "Project partnering in Norwegian construction industry." Energy Procedia, 96, pp 241-252.

Howell, G. A. 2011. "Where LCI and DBIA agree and where we differ." a presentation at the January 11, 2011 meeting of DBIA NorCal, Oakland, CA, 2011.

Ingvaldsen, T. and Edvardsen, D. F. 2007. Effektivitetsanalyse av byggeprosjekter: måleog analysemetode basert på referansetesting av 122 norske boligprosjekter fra perioden 2000-2005, SINTEF Byggforsk.

Larssen, P. F., Engebø, A., Lædre, O. and Klakegg, O. J. 2019. «Contracts and Culture in a Partnering Project." 10th Nordic Conference on Construction Economics and Organization. Emerald Publishing Limited. Vol. 2, pp 49-57.

Lean Construction Institute. 2016. Triangle-new-2016 [Online]. [Accessed 11.02 2020]. 
Matthews, O. and Howell, G. A. 2005. "Integrated project delivery an example of relational contracting." Lean construction journal, 2(1), pp 46-61.

Miller, J. B., Garvin, M. J., Ibbs, C. W. and Mahoney, S. E. 2000. "Toward a new paradigm: Simultaneous use of multiple project delivery methods." Journal of Management in Engineering, 16(3), pp 58-67.

Oakland, J. S. and Marosszeky, M. 2017. Total construction management: Lean quality in construction project delivery, Routledge. Devon, U.K.

Paro, P. E. P. and Gerolamo, M. C. 2017. "Organizational culture for lean programs." Journal of Organizational Change Management, 30(4), pp 584-598.

Parrish, K., Wong, J.-M., Tommelein, I. D. and Stojadinovic, B. 2008. Set-based design: case study on innovative hospital design. Proc. 6th Annual Conference of the International Group for Lean Construction (IGLC). Manchester, U.K., 16-18 Jul 2008. pp 413-424.

Saunders, M. N. K., Lewis, P. and Thornhill, A. 2016. Research methods for business students, Harlow, Pearson.

Simonsen, S. H. F., Skoglund, M. H., Engebø, A., Varegg, B. E. and Lædre, O. 2019. Effects of IPD in Norway - A Case Study of the Tønsberg Project. Proc. 27th Annual Conference of the International Group for Lean Construction (IGLC). Dublin, Ireland, 3-5 Jul 2019. pp 251-262.

Stehn, L. and Höök, M. 2008. "Lean principles in industrialized housing production: the need for a cultural change." Lean Construction Journal, 4(1), pp 20-33.

Thomsen, C., Darrington, J., Dunne, D. and Lichtig, W. 2009. "Managing integrated project delivery." Construction Management Association of America (CMAA), McLean, VA, 105.

Tommelein, I. D. 1998. "Pull-driven scheduling for pipe-spool installation: Simulation of lean construction technique." Journal of construction engineering and management, 124(4), pp 279-288.

Willcocks, L. P. and Kern, T. 1998. "IT outsourcing as strategic partnering: the case of the UK inland revenue." European Journal of Information Systems, 7, pp 29-45.

Wøien, J., Hosseini, A., Klakegg, O. J., Lædre, O. and Lohne, J. 2016. Partnering Elements' Importance for Success in the Norwegian Construction Industry. Energy Procedia, 96, pp 229-240.

Yin, R. K. 2018. Case study research and applications: design and methods, SAGE. Los Angeles, USA.

Zuo, J. and Zillante, G. 2005. "Project culture within construction projects: a literature review." Proc. 13th Annual Conference of the International Group for Lean Construction (IGLC). Sydney, Australia, 19-21 Jul 2005. pp 353-361. 